\title{
Parametric Study of the Effect of Ground Anchor on Deep Excavation Stability
}

\author{
Aditya Putra Pratama*, Hary Christady Hardyatmo, Fikri Faris \\ Department of Civil and Environmental Engineering, Universitas Gadjah Mada, Yogyakarta, INDONESIA \\ Jalan Grafika No 2 Yogyakarta \\ Corresponding authors: appspl10@gmail.com
}

SUBMITTED 10 July 2019 REVISED 30 August 2019 ACCEPTED 15 September 2019

\begin{abstract}
Apartment construction is mostly carried out by including deep excavation works. However, excavation causes land instability; hence, the work needs to be done by a particular handler. In some cases, deep excavation is carried out on soft soil, which has a very high level of soil instability; therefore, a specific handling method such as ground anchor is required as an alternative. This study aims to conduct parametric research on the effect of using anchors on the stability of deep excavation. First, anchors of various slopes were modelled while varying the number of anchors up to four pieces. From the results of the study, the requirements representing the most efficient use of anchors were selected, and then various anchor bond lengths were modelled. Finally, the effect of applying various magnitudes of prestress forces to the anchor was determined. All of the models were examined to determine the influence on the stability of the deep excavation by observing the horizontal displacement and the forces that occur on the secant pile. From the analysis results, it can be concluded that the most effective slope angle is $0^{\circ}$. The displacement and forces occurred in the secant piles on the use of two, three, or four anchors has not a significant difference. The application of a higher prestress force on the anchor would yield better results as long as it is not exceeding $200 \mathrm{kN}$. However, in the case of an apartment building's plans in Surabaya, the optimal anchor usage was found to be the use of two anchors with a $45^{\circ}$ slope, $4.5 \mathrm{~m}$ for the first (A) and second (B) anchor bond lengths, $15 \mathrm{~m}$ free length anchor, $2.5 \mathrm{~m}$ vertical anchor distance, $1.2 \mathrm{~m}$ horizontal anchor distance, and the application of $200 \mathrm{kN}$ prestress force.
\end{abstract}

KEYWORDS Deep Excavation; Ground Anchor; Secant Pile; Parametric Study; Prestresses

(c) The Author(s) 2020. This article is distributed under a Creative Commons Attribution-ShareAlike 4.0 International license.

\section{INTRODUCTION}

The need for excavation stability is an important factor in infrastructure development. There are many deep excavation methods, as explained by Wang et al. (2016). Incorrect implementation and handling of deep excavation can cause slope failure. Slope failure can cause losses such as damage to surrounding buildings, damage to heavy equipment, slowness of work processes, and even degradation of work safety. Therefore, reinforcement is required to avoid the damage caused by deep excavation instability.

There are several similar studies about soil nailing in deep excavations. Josifovski et al. (2012) reported that modelling deep excavations with multiple anchors by numerical analysis can help describe all the effects in the process of excavation in the presence of difficult materials and loading conditions. López et al. (2017) used a finite element method to estimate the earth pressures transferred to a pile, the moment and shear forces on the pile, and the anchor's stresses. Alsubal et al. (2017) also reported that angles of anchor give different results in deep excavation stability.

The supports of deep excavations have a very important role in nearby existing buildings (Zumrawi \& El-Amin, 2016) and the construction itself. The stability of deep excavations can be handled and improved via various methods, one of which is to use a ground anchor. An overview by Budania \& Arora (2016) stated that ground anchor has many advantages as regards construction, performance, and cost aspects. However, there are not many studies discussed the use of anchor in deep excavations strengthened by secant piles. Thus, this study 
aims to conduct a parametric study on the effect of using an anchor on the stability of deep excavations.

\section{RESEARCH METHOD}

The research is based on the development of an apartment building's plans in Surabaya. The analysis was started by modelling anchors of various slopes, with the number of anchors reaching four pieces. Based on the analysis results, the requirements representing the most efficient use of anchor were selected, and then various anchor bond lengths were modelled accordingly. Finally, the effects of providing various magnitudes of prestress force were determined. All the models were examined to determine the influence on the stability of the deep excavation by observing the horizontal displacement and the forces that occur in the secant pile. Moreover, the Plaxis v.8.6 software was used as a modelling tool, and all the soil layers behind the secant pile were assumed to be homogenous soil, according to the results of conducted investigation. The vertical and horizontal distances of each anchor were determined as $2.5 \mathrm{~m}$ and $1.2 \mathrm{~m}$, respectively.

\subsection{Free Length Anchor Design}

The minimum unbound length (free length) of an anchor is $4.5 \mathrm{~m}$ for the wire type and $3 \mathrm{~m}$ for the tendon type. However, longer unbound lengths can be used for the following:

a) Determining the minimum bond length behind the potential critical failure line

b) Determining the bond zone for anchor

c) Ensuring the overall stability of the anchor

d) Accommodating anticipated long-term movement

Overall, the unbound length is $\mathrm{H} / 5$ or $1.5 \mathrm{~m}$ behind the critical failure potential line to accommodate the transfer of minor loads to the concrete column above the anchor in the bond zone. This is illustrated in Figure 1, where $\chi$ is equal to $1.5 \mathrm{~m}$ or $0.2 H$ (the highest value is selected).

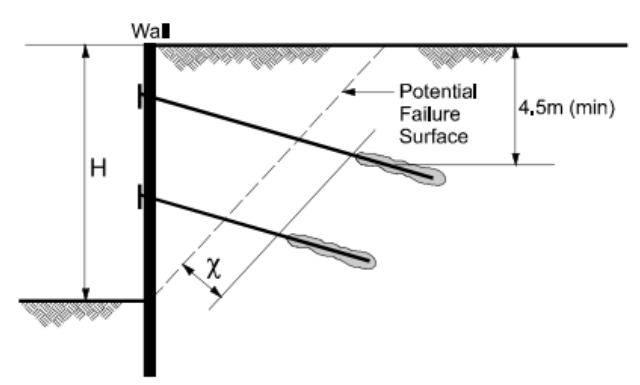

Figure 1. Free length design (FHWA,1999)

\subsection{Planning the Bond Length in Anchor}

The equation used in planning bond lengths on anchors is shown in Equation (1) (FHWA, 1999):

Bond length $=\frac{T S F}{\text { Estimated ultimate transfer load }}$

where $T$ is the load that works on the anchor. In the analysis, determining the safety factor value $(S F)$ is based on conditions in the field. In general, the $S F$ value is taken as 2 .

The bond length on anchors is generally $4.5 \mathrm{~m}$ to $12 \mathrm{~m}$ because lengths exceeding $12 \mathrm{~m}$ cannot be added unless a particular method that allows the transfer of loads from the base to the tip of the anchor is employed. Littlejohn (1981) suggests the use of Equation (2) for the design of bondedlength anchor on cohesionless soils.

$$
T=K \pi D L \sigma_{\mathrm{V}}^{\prime} \tan \phi
$$

where $\mathrm{T}$ is the stress on anchor, $K$ is the soil pressure coefficient $(1.4-2,3), D$ is the bond length diameter, $L$ is the anchor bond length, $\sigma_{\mathrm{v}}$ is the effective soil pressure, and $\phi$ is the soil friction angle.

Moreover, Littlejohn (1981) suggests the use of Equation (3) for the design of bonded-length anchor on cohesive soils.

$$
T=\pi D L \alpha c_{u}
$$

where $T$ is the stress on anchor, $D$ is the bond length diameter, $L$ is the anchor bond length, $\alpha$ is the adhesion factor $(0.45-0.6)$, and $c_{u}$ is the soil cohesion parameter. 


\subsection{Modelling Input Parameters}

Secondary data were used as a modelling input parameter. The modelling input parameters consist of soil input parameters (Table 1), secant pile (Table 2), anchor (Table 3), and bond length (Table 4). Excavation modelling in the field can be seen in Figure 2 and 3.

Table 1. Soil input parameter (Testana Engineering, 2015)

\begin{tabular}{|c|c|c|c|c|c|c|}
\hline $\begin{array}{l}\text { Depth } \\
\text { (m) }\end{array}$ & Soil Type & $\mathrm{N}$ & $\begin{array}{l}\mathrm{c} \\
(\mathrm{kPa})\end{array}$ & $\begin{array}{l}\varphi \\
\left({ }^{\circ}\right)\end{array}$ & $\begin{array}{l}\gamma_{\text {sat }} \\
\left(\mathrm{kN} / \mathrm{m}^{3}\right. \\
)\end{array}$ & $\begin{array}{l}\mathrm{E} \\
(\mathrm{kPa})\end{array}$ \\
\hline $0-14$ & silty clay & 1 & 7 & 7 & 15.0 & 3,000 \\
\hline $14-23$ & $\begin{array}{l}\text { clayey-sandy } \\
\text { silt }\end{array}$ & 16 & 90 & 20 & 18.0 & 30,000 \\
\hline $23-28$ & silty sand & 31 & 20 & 30 & 19.5 & 30,000 \\
\hline $28-40$ & clayey silt & 21 & 100 & 8 & 18.5 & 30,000 \\
\hline $40-60$ & $\begin{array}{l}\text { alternation } \\
\text { sand and clay }\end{array}$ & 28 & 150 & 8 & 18.5 & 40,000 \\
\hline
\end{tabular}

Table 2. Secant pile input parameter (Testana Engineering, 2015)

\begin{tabular}{lll}
\hline Parameter & Value & Units \\
\hline Depth & 12 & $\mathrm{~m}$ \\
Pole diameter & 0.8 & $\mathrm{~m}$ \\
Area & 0.50 & $\mathrm{~m}^{2}$ \\
Distance & 1.2 & $\mathrm{~m}$ \\
$I$ & 0.02 & $\mathrm{~m}^{4}$ \\
$E$ & $23,500,000$ & $\mathrm{kPa}$ \\
$E I$ & $472,495.53$ & $\mathrm{kNm} / \mathrm{m}$ \\
$E A$ & $11,812,388.38$ & $\mathrm{kN} / \mathrm{m}$ \\
Concrete density & 24 & $\mathrm{kN} / \mathrm{m}^{3}$ \\
$W$ & 12.06 & $\mathrm{kN} / \mathrm{m}^{2}$ \\
$E I^{*}$ & $393,746.28$ & $\mathrm{kNm} / \mathrm{m}$ \\
EA & $9,843,656.98$ & $\mathrm{kN} / \mathrm{m}^{*}$ \\
winput & 10.05 & $\mathrm{kN} / \mathrm{m}^{2}$ \\
\hline
\end{tabular}

Table 3. Anchor input parameter

\begin{tabular}{lll}
\hline Parameter & Value & Unit \\
\hline$n$ & 4 & piece \\
$d$ & 0.02 & $\mathrm{~m}$ \\
$S h$ & 1.2 & $\mathrm{~m}$ \\
$A$ & 0.000565 & $\mathrm{~m} 2$ \\
$E$ & $1.95 \mathrm{E}+08$ & $\mathrm{kPa}$ \\
$E A$ & 110258.6 & $\mathrm{kN} / \mathrm{m}$ \\
$F$ & 625 & $\mathrm{kN}$ \\
\hline
\end{tabular}

Table 4. Anchor bond length input parameter

\begin{tabular}{lll}
\hline Parameter & Value & Unit \\
\hline$d$ & 0.2 & $\mathrm{~m}$ \\
$A$ & 0.03 & $\mathrm{~m}^{2}$ \\
$E$ & $23,500,000$ & $\mathrm{kPa}$ \\
$E A$ & $738,274.30$ & $\mathrm{kN} / \mathrm{m}$ \\
$s$ & 1.20 & $\mathrm{~m}$ \\
$E A^{*}$ & $615,228.60$ & $\mathrm{kN} / \mathrm{m}$ \\
\hline
\end{tabular}

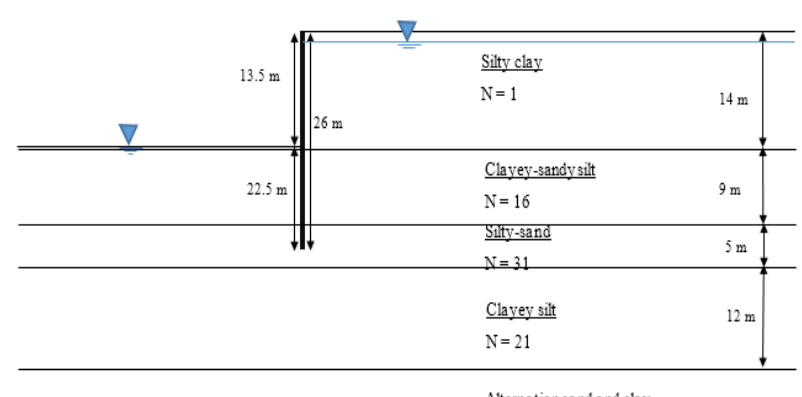

Alternation sand and clay

$\mathrm{N}=28$

Figure 2. Field condition

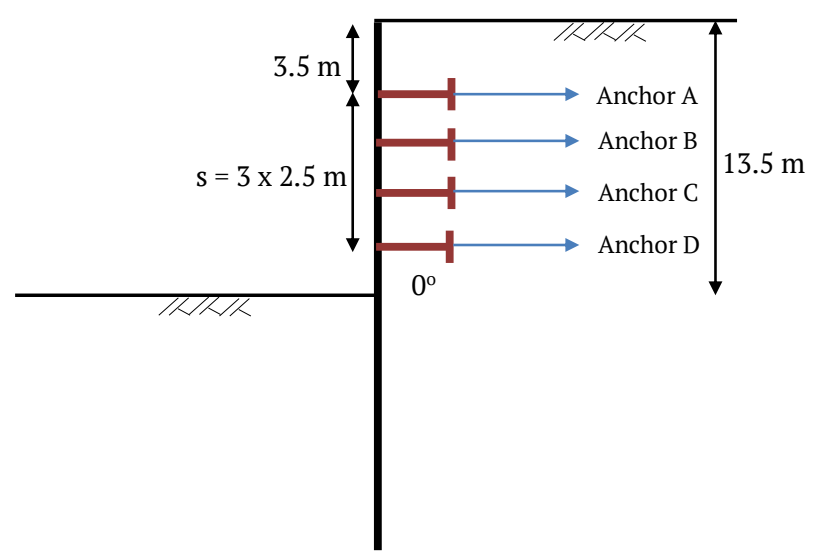

Figure 3. Naming and distance determination of anchor

\section{RESULT AND DISCUSSION}

\subsection{Free Length Anchor Design}

Based on the Federal Highway Administration (FHWA, 1999) standard, the minimum free length in anchor is $1.5 \mathrm{~m}$ or 0.2 times the secant pile height above the slope failure. Before the reinforcement, deep excavation modelling is conducted to determine the slope failure line. The modelling results can be seen in Figure 4 . 


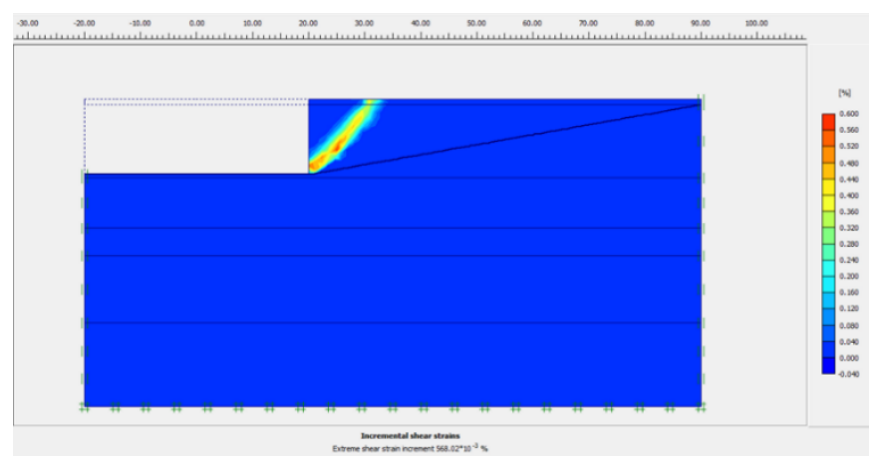

Figure 4. Shading of total displacement without reinforcement on deep excavation modelling

The slope failure line is denoted by yellow. The free length requirement at the angle of $0^{\circ}$ anchor is $12 \mathrm{~m}$ plus $2.7 \mathrm{~m}$ (0.2 times the secant pile height from the surface of the soil excavation). Thus, the free length is determined to be as long as $15 \mathrm{~m}$.

Gunawan, et al. (2017) reported that if the anchor length passes the effective value of the $L / d$ range (400-650), the $S F$ will not change significantly. However, in this case study, the free length needs to be more than $15 \mathrm{~m}$ so that the bond length will be built on hard soil.

\subsection{The Anchor Slope Effect}

\subsubsection{Anchor Force}

Based on the graph of the relationship between the value of $T$ and the anchor slope, anchor $A$ tends to feature an increase in stress with an increase in the anchor slope. For anchor B, the stress tends not to change with the increase in the anchor slope. Anchors C and D show tendencies of decrease in the anchor stress with the increase in the anchor slope. This shows that locating anchors above half the height of the secant pile, measured from the bottom surface of the excavated soil, tends to increase the $T$ value due to the increase in the anchor slope. However, locating the anchors below half the height of the secant pile, measured from the bottom surface of the excavated soil, tends to decrease the $\mathrm{T}$ value due to an increase in the anchor slope. Figure 5 shows the relationship between the anchor stress (T) and the slope of the anchor considering four anchors.

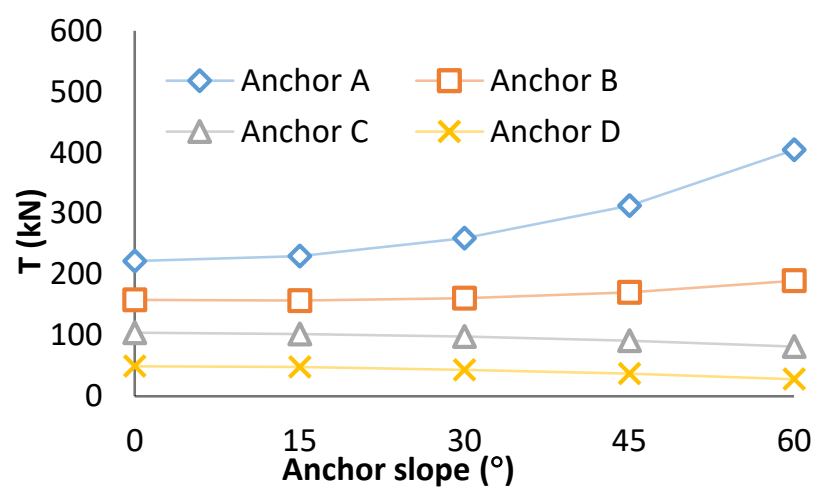

Figure 5. The relationship between the anchor stress $(T)$ and the slope of the anchor considering four anchors

\subsubsection{Secant Pile}

The maximum horizontal displacement, moment, and shear in a secant pile show the same tendency, which is an increase in value with an increase in the anchor slope. The levels of increase in the maximum horizontal displacement, moment, and shear appear sharper after the anchor slope exceeds $45^{\circ}$. Thus, it can be concluded that an anchor slope exceeding $45^{\circ}$ is not effective.

In the Figure 6 to 8, the effects of the increase in anchor slope on the maximum horizontal displacement, moment, and shear on the secant pile also show that the use of two to four anchors features results that are not much different; on the graph, the relationship lines corresponding to the usages of two to four anchors almost coincide. Thus, it can be concluded that the use of more than two anchors is not efficient.

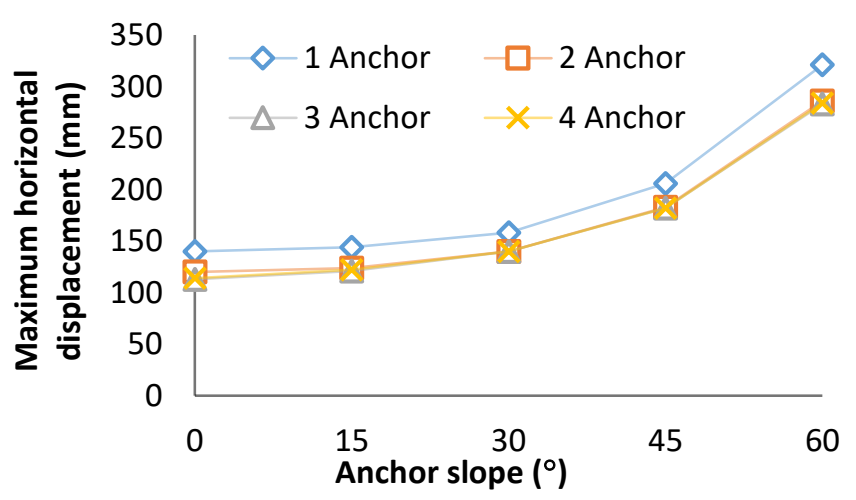

Figure 6 . The relationship between the maximum horizontal displacement $\left(\delta_{h}\right)$ on the secant pile and the anchor slope 


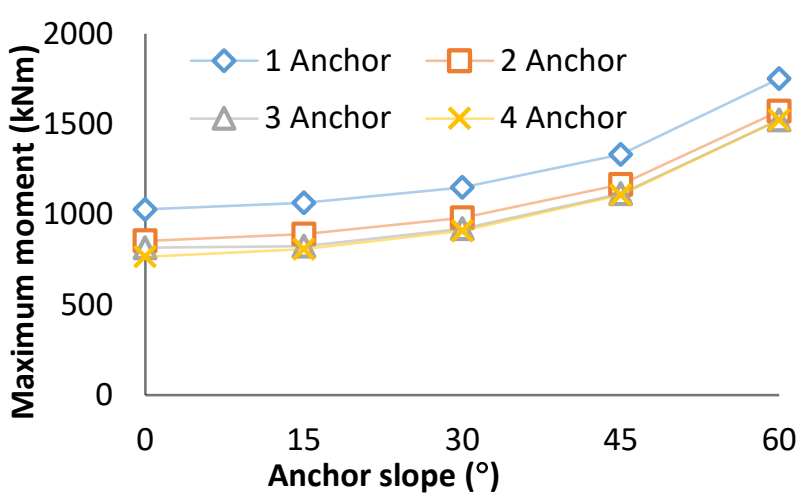

Figure 7. The relationship between the maximum moment on the secant pile and the anchor slope

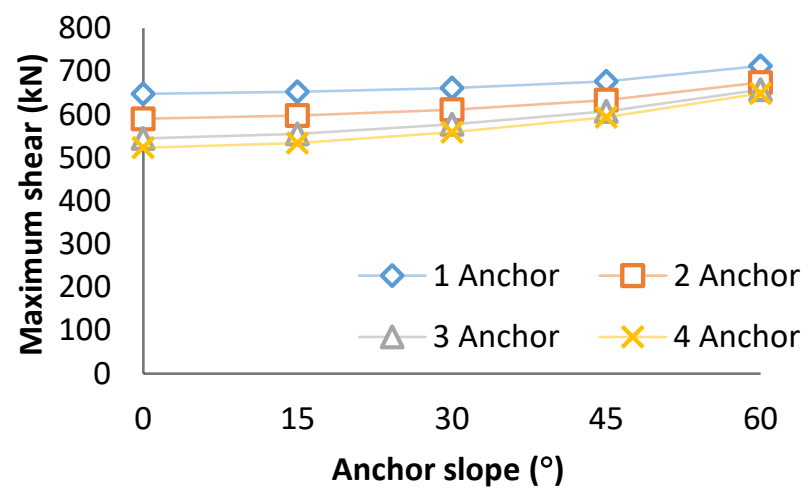

Figure 8. The relationship between the maximum shear of the secant pile and the anchor slope

\subsubsection{Bond Length Analysis with the FHWA Method (1999)}

Figure 9 shows the relationship between the bond length $L_{b}$ and the anchor slope considering four anchors according to FHWA method (1999). From the obtained analysis results, the anchor slopes of $0^{\circ}$ to $30^{\circ}$ show the need for an anchor bond length of over $12 \mathrm{~m}$. This is because the anchor bond length is planted on hard soil and thus is required to be very long. In this case, the $45^{\circ}$ anchor slope is the minimum to be embedded at hard soil so that the bond length is relatively short. According to FHWA (1999), the recommended maximum bond length is $12 \mathrm{~m}$.

\subsubsection{Bond Length Analysis with Littlejohn Method (1981)}

Figure 10 shows the relationship between the bond length $L_{b}$ and the anchor slope considering four anchors according to Littlejohn method (1981). The required bond length $\left(L_{b}\right)$ obtained by the analysis using the Littlejohn (1981) method is longer than that obtained by analysis done using the FHWA (1999) method. However, the relationships between the required bond length and the anchor slope show the same tendency.

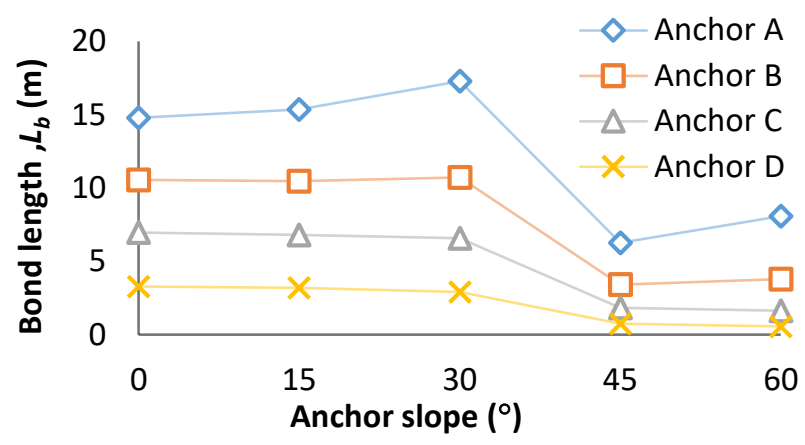

Figure 9. The relationship between the bond length $L_{b}$ and the anchor slope considering four anchors based on FHWA (1999)

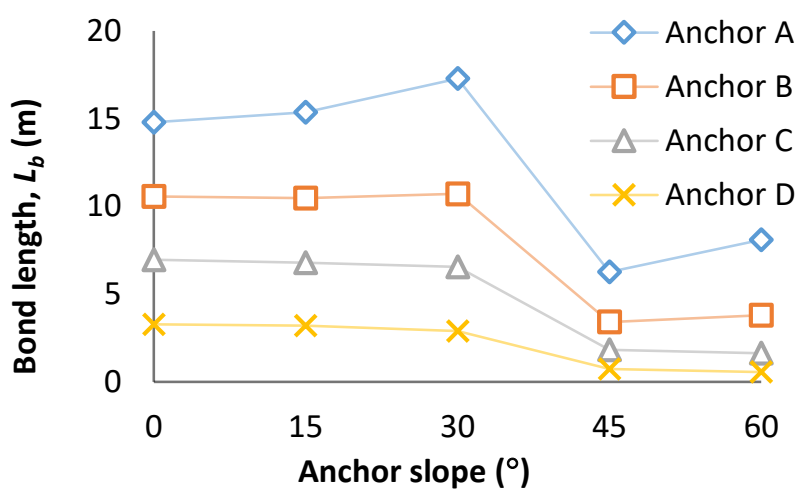

Figure 10. The relationship between the bond length $L_{b}$ and the anchor slope considering four anchors according to Littlejohn (1981)

Angled slope analysis shows that the slope angle $0^{\circ}$ is the most effective because the horizontal displacement and the forces acting on the secant pile are lowest; this also applies to forces acting on the anchor. Singh \& Shrivastava (2017) reported the same result, that a $0^{\circ}$-angled anchor is more efficient in providing stability to the slope. However, in this case study, the $0^{\circ}$ angled anchor requires a very long free length compared with that required by the $45^{\circ}$ angled anchor due to the difference in soil layer. For this case study, the best anchor slope angle is $45^{\circ}$.

In the analysis of the anchor slope, it can also be concluded that the use of more than two anchors does not give significantly different results (Figure 5 to Figure 7). The displacement and forces that occur in the secant piles on the use of 
two anchors are not much different from those that occur when three and four anchors are used.

\subsection{Effect of Anchor Bond Length}

The anchor bond length requirements were analyzed using two methods, which are the FHWA (1999) and Littlejohn (1981) methods. The results show that the required anchor bond length determined by the FHWA (1999) method is shorter. Thus, the anchor bond length obtained from calculations using the FHWA (1999) method is used as the minimum length of the anchor. For the use of one anchor, the anchor bond length is $9.4 \mathrm{~m}$ (anchor $\mathrm{A}$ ), while for the use of two anchors, the bond lengths are $6.8 \mathrm{~m}$ (anchor $\mathrm{A}$ ) and $4.2 \mathrm{~m}$ (anchor B).

The analysis results presented in Table 5 and Table 6 show that there are no significant changes in the horizontal displacement $\left(\delta_{\mathrm{h}}\right)$, moments, and maximum shear forces. In addition, there is a condition where the anchor bond length penetrates a harder soil layer. However, the results show that even though the bond length penetrates a harder soil and is extended to $12 \mathrm{~m}$, there is no significant effect on the horizontal displacement and forces on the secant pile. The anchor bond length reduction to a minimum limit of $4.5 \mathrm{~m}$ results in an increase in the horizontal displacement value and the forces on the secant pile even though slightly.

Table 5. The effect of adding a bonded-length anchor to secant pile using one anchor.

\begin{tabular}{|c|c|c|c|c|c|c|c|}
\hline \multirow[t]{3}{*}{ Information } & \multicolumn{4}{|c|}{$\begin{array}{l}\text { Bond length on } \\
1 \text {-anchor model } \\
(\mathrm{m})\end{array}$} & \multirow[t]{2}{*}{$\delta_{\mathrm{h}}$} & \multirow[t]{2}{*}{$\begin{array}{l}\text { Max } \\
\text { moment }\end{array}$} & \multirow[t]{2}{*}{$\begin{array}{l}\text { Max } \\
\text { shear }\end{array}$} \\
\hline & Anch & & & & & & \\
\hline & $\mathrm{A}$ & B & $\mathrm{C}$ & $\mathrm{D}$ & $\mathrm{mm}$ & $\mathrm{KNm} / \mathrm{m}$ & $\mathrm{kN}$ \\
\hline \multirow{5}{*}{$\begin{array}{l}\text { Bond length } \\
\text { on } 1 \text { layer }\end{array}$} & 4.5 & - & - & - & 238 & 1170 & 571.0 \\
\hline & 9.4 & - & - & - & 233 & 1150 & 568.0 \\
\hline & 10.0 & - & - & - & 232 & 1150 & 568.0 \\
\hline & 11.0 & - & - & - & 231 & 1150 & 568.0 \\
\hline & 12.0 & - & - & - & 231 & 1150 & 569.7 \\
\hline
\end{tabular}

Table 6 . The effect of adding bonded-length anchor to secant pile using two anchors

\begin{tabular}{|c|c|c|c|c|c|c|c|}
\hline \multirow{3}{*}{ Information } & \multirow{2}{*}{\multicolumn{4}{|c|}{$\begin{array}{l}\text { Bond length on } 1 \\
\text { anchor model (m) } \\
\text { Anchor }\end{array}$}} & \multirow{3}{*}{$\begin{array}{l}\delta_{\mathrm{h}} \\
\mathrm{mm}\end{array}$} & \multirow{3}{*}{$\begin{array}{l}\text { Max } \\
\text { mom } \\
\text { ent } \\
\text { KNm/ } \\
\text { m }\end{array}$} & \multirow{3}{*}{$\begin{array}{l}\text { Max } \\
\text { shear }\end{array}$} \\
\hline & & & & & & & \\
\hline & A & $\mathrm{B}$ & $\mathrm{C}$ & $\mathrm{D}$ & & & \\
\hline & 4.5 & 4.2 & - & - & 212 & 1020 & 538 \\
\hline Bond length & 6.8 & 4.2 & - & - & 210 & 1010 & 537 \\
\hline on 1 layer & 9.0 & 6.0 & - & - & 210 & 1010 & 536 \\
\hline & 12.0 & 8.0 & - & - & 209 & 1010 & 536 \\
\hline $\begin{array}{l}\text { Bond length } \\
\text { penetrates the } \\
\text { harder layer }\end{array}$ & 12.0 & 12.0 & - & - & 209 & 1010 & 535 \\
\hline
\end{tabular}

\subsection{The Effect of Prestress Force}

Figure 11, 12, and 13 show the relationship between the prestress force and the maximum horizontal displacement, the maximum moment, and the maximum shear force, respectively. Two anchors usage provides a better result as regards the maximum moment, shear, and horizontal displacement of the secant pile than one anchor usage. However, applying a prestress force of more than $200 \mathrm{kN}$ will increase the maximum moment, even though the maximum shear and horizontal displacement are decreasing. Therefore, combining two anchors usage and 200 $\mathrm{kN}$ of prestressing force is the best option to have an optimum result of the maximum moment, shear, and horizontal displacement of the secant pile.

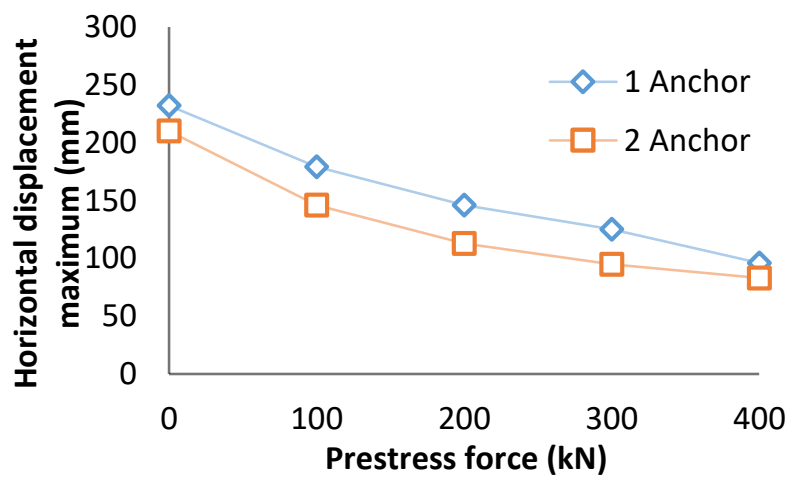

Figure 11. The relationship between the maximum horizontal displacement $\left(\delta_{h}\right)$ and the prestress force 


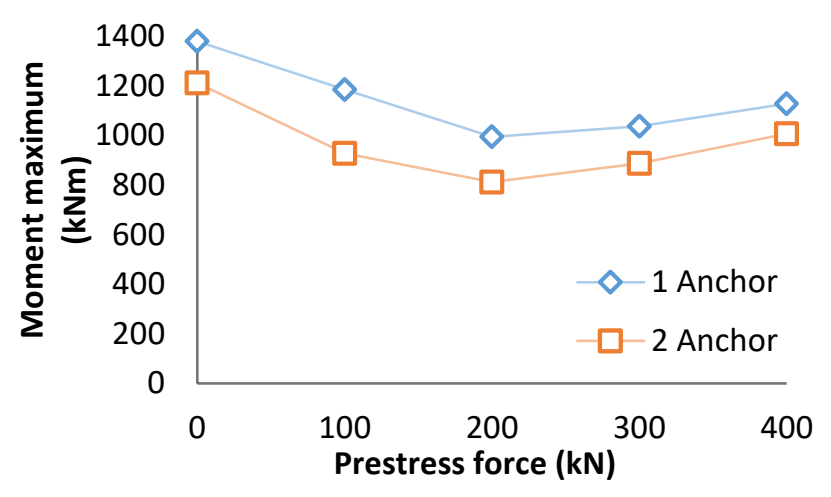

Figure 12. The relationship between the maximum moment and the prestress force.

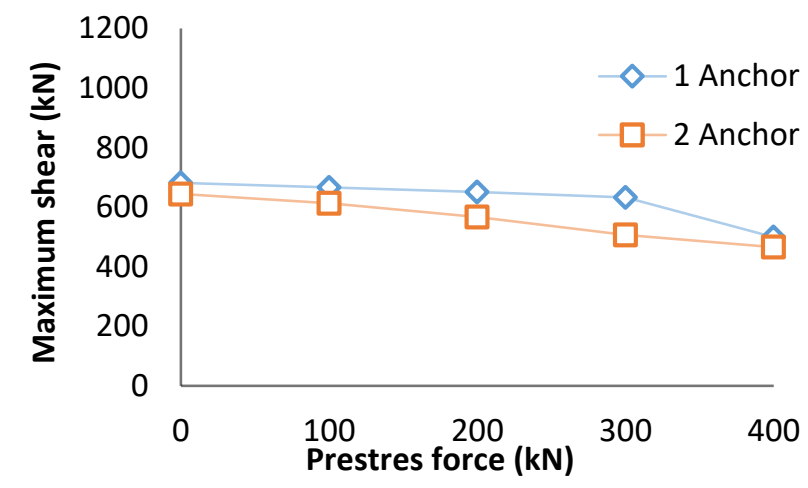

Figure 13. The relationship between the maximum shear and prestress force.

\section{CONCLUSIONS}

The analysis result shows that the slope angle $0^{\circ}$ is the most effective due to the lowest horizontal displacement, the forces acting on the secant pile, and the forces acting on the anchor. In addition, the displacement and forces that occur in the secant piles on the use of two anchors are not much different from those that occur when three and four anchors are used. The application of a higher prestress force on the anchor would yield better results as regards the maximum shear and horizontal displacement of the secant pile. However, applying a prestress force exceeding $200 \mathrm{kN}$ would increase the maximum moment of the secant pile.

In the case of an apartment building's plans in Surabaya, the optimal anchor usage was found to be the use of two anchors with a $45^{\circ}$ slope, $4.5 \mathrm{~m}$ for the first (A) and second (B) anchor bond lengths, $15 \mathrm{~m}$ free length anchor, $2.5 \mathrm{~m}$ vertical anchor distance, $1.2 \mathrm{~m}$ horizontal anchor distance, and the application of $200 \mathrm{kN}$ prestress force.

\section{DISCLAIMER}

The authors declare no conflict of interest.

\section{REFERENCES}

Alsubal, S., Harahap, I.S.H. and Muhammad Babangida, N., 2017. A Typical Design of Soil Nailing System for Stabilizing a Soil Slope: Case Study. Indian Journal of Science and Technology.

Budania, R. and Arora, D.R.P., 2016. Soil Nailing for Slope Stabilization: An Overview. International Journal of Engineering Science and Computing.

FHWA, 1999. Geothecnical Engineering Circular No. 4 - Ground Anchors and Anchored Systems. Washington. Washington, DC.

Gunawan, I., Surjandari, N.S. and Purwana, Y.M., 2017. The study on length and diameter ratio of nail as preliminary design for slope stabilization. In: Journal of Physics: Conference Series.

Josifovski, J., Gjorgjevski, S. and Jovanovski, M., 2012. Numerical analysis of $20.5 \mathrm{~m}$ deep excavation with anchored diaphragm wall. In: Geotechnical Aspects of Underground Construction in Soft Ground - Proceedings of the 7th International Symposium on Geotechnical Aspects of Underground Construction in Soft Ground.

Littlejohn, G.S., 1981. Design Estimation of the Ultimate Load-Holding CAapacity of Ground Anchors. Journal of the Boston Society of Civil Engineers Section, American Society of Civil Engineers.

López, S., Sanhueza, C. and Candia, G., 2017. Anchored Piles in Deep Excavations: A Case Study. 16th World Conference on Earthquake Engineering.

Singh, S. and Shrivastava, A.K., 2017. Effect of Soil Nailing On Stability of Slopes. International Journal for Research in Applied Science \& Engineering Technology (IJRASET). 
Testana Engineering, 2015. Laporan Penyelidikan Geoteknik - Proyek Grand Dharmahusada Lagoon. Surabaya.

Wang and et al, 2016. Concept and characters of deep excavation groups in urban underground space development. The 15th Asian Regional Conference on Soil Mechanics and Geotechnical
Engineering.

Zumrawi, M.M.E. and El-Amin, A., 2016. Importance of Deep Excavation Support and Its Influence on Adjacent Buildings. 7th Annual Conference for Postgraduate Studies and Scientific Research. 